\title{
Research and Design of Capsule-like Robot Wireless Powering System Based on Class-E Inverter
}

\author{
A.N. Wang \\ Northeastern University \\ Shenyang Liaoning, China \\ Z.J. Huang \\ Northeastern University \\ Shenyang Liaoning, China
}

\author{
Z.B. $\mathrm{Yu}$ \\ Northeastern University \\ Shenyang Liaoning, China \\ Q. Shao \\ Shenyang Institute of Automation Chinese Academy of \\ Sciences \\ Shenyang Liaoning, China
}

\begin{abstract}
The power supply problem is one of the main problems facing the capsule-like robot technology. There are many issues worthy of further exploration. Such as the transmitter power and efficiency is not high, the performance can be greatly reduced when increase the using frequency, coil position stability problems and many other issues. Aiming at these problems, the paper studies on the method of improving the transmitter power, efficiency and operating frequency. This system chooses the class- $E$ inverter as the transmitter of the inverter, make optimization design and parametric modelling of class-E inverter. This paper analyzed the transmitter circuit characteristics, parameters of actual circuit on the circuit performance. Finally, This paper tested the wireless power supply system. The test results show that, the wireless power supply system has high frequency, high power, high efficiency, and the loop current with the input power supply voltage is in linear relation, the system has good repetition.
\end{abstract}

Keywords-wireless power supply; class-E inverter; capsule-like robot; frequency tracker; positional stability

\section{INTRODUCTION}

The wireless power supply system had become the most critical problems in the development of capsule endoscopy technology. Through the integration of wireless power supply function in vitro, It could not only reduce the volume, but also provided a large number of continuous power to lay a solid foundation for the capsule robot functions more perfect, high precision measurement. Countries such as Japan, the United States and Europe had carried out extensive and in-depth research technology of wireless power supply system , and a large number of tests had been carried out [1-7]. The capsule robot although wireless power supply system was one of the wireless power, but due to the particularity of the application and structure, its applications was different from others. It was

in its infancy and there were a lot of problem, such as the structure and application of stability problem caused by the particularity of the position, transmitter power, inefficient, high frequency effect and use frequency to high frequency. These technical problems limited the use of capsule robot and further perfect. Therefore, in view of these aspects of research was very necessary.
This passage was divided into three parts: (1) The overall design for the capsule robot wireless power supply system: simple introduction of the system composition. (2) Performance analysis of class $\mathrm{E}$ inverter: analyzing and summing up the effect of practical circuit parameters for the performance of the circuit, and the inverter was implemented. (3) Wireless power supply system performance test and contrast.

\section{The DESIGN OF CAPSUle Robot WIRELESS POWER SUPPLY SYSTEM}

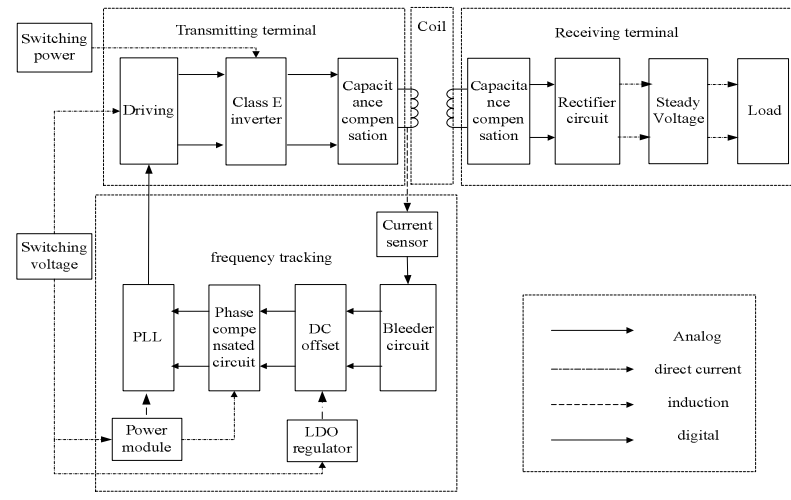

FIGURE I. OVERALL FUNCTION MODULE OF WIRELESS POWER SUPPLY SYSTEMS

For the overall structure of the capsule robot wireless power supply system was shown in fig.1. It was mainly consisted of the transmitter, the receiver circuit and control circuit. Transmitter circuit mainly included the class E inverter, driver circuit, harmonic compensation circuit and the transmitter coil. Receiving circuit mainly included the receiving coil, harmonic compensation circuit, rectifier circuit, voltage regulator circuit. Control circuit used frequency tracker, mainly including current sensor, voltage circuit, DC bias circuit, phase compensation circuit, phase lock loop, LDO regulating circuit, and power conversion module. 


\section{PERFORMANCE ANALYSIS OF ClASS E INVERTER}

The capsule robot system for wireless power supply had the position stability problems [8]. The passage solved the problem by improving the uniformity of magnetic field [9] and the minimum energy use of the coil coupling could meet the receiving end's. But this method of power supply belonged to the weak coupling, having a low coupling efficiency. So the transmitter high power was very necessary. Transmitter loss was mainly from inverter loss and transmission circuit mismatch loss. The inverter loss mainly was concentrated in the switch of the inverter switching loss [10-11]. So improving the efficiency of transmitting terminal inverter [12] was also very important for the whole system. Via the study, it was found that the high frequency power density could improve the system, reduce the size of the device, and improve the efficiency of power transmission [13], so the high frequency was also very important. Studies and experiments showed that class $E$ inverter with high efficiency condition also could be applied into the relatively high frequency, high power occasion.

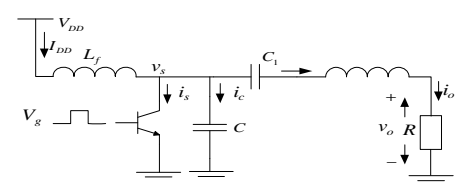

(a) Schematics of Class-E inverter

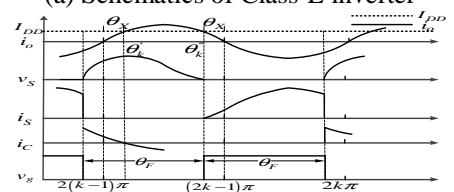

(b) Waveform diagram of Class-E inverter

FIGURE II. CLASS-E INVERTER SCHEMATICS AND WAVEFORM DIAGRAM

2.

We get the following important relationship can from fig.

$$
\begin{aligned}
& I_{D D}=I_{m} \sin \theta_{X} \\
& C=\frac{1}{\omega_{o} R} \beta \\
& V_{D D}=\frac{I_{m} \alpha}{\omega_{0} C} \\
& P_{\text {out }}=\frac{1}{2} I_{m}^{2} R \\
& C_{1}=\frac{C}{\omega_{o}^{2} L_{1} C-\gamma}
\end{aligned}
$$

It was found that the influence of different transmitting terminal parameters on the circuit through a lot of experiment, and the conclusion was drawn in fig. 3. Class E inverter's efficiency could be seen from control signal and switch tube voltage waveform, and emission current could be got through the inductor voltage.In fig. 3 (a), vertical or vertical component of the line meant the effect for the switch voltage peak value. The lateral or horizontal component meant the influence for switch voltage waveform width. The switch voltage was suit for ZVS, ZDS to realize non-loss. In fig. 3 (b), it was pointed out that the influence of parameters on the induced voltage. The length and direction of the line could show how various parameters affect the induced voltage.

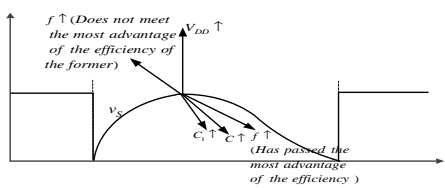

(a) Switching voltage relationship with each parameter

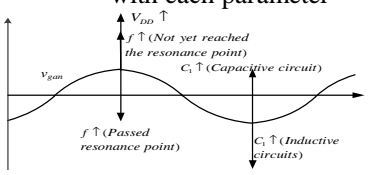

(b) Induced voltage relationship with each parameter

FIGURE III. RELATIONSHIP WITH EACH PARAMETER CIRCUIT CHARACTERISTICS

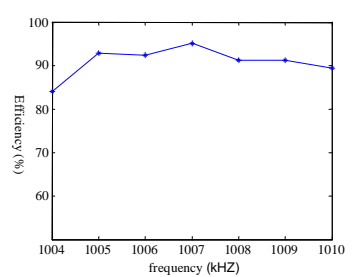

(a) Efficiency and frequency characteristics

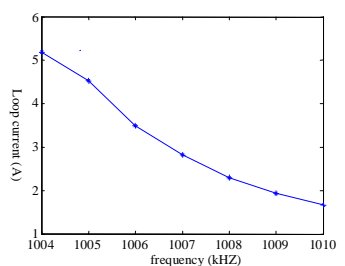

(b) Loop current and frequency characteristics

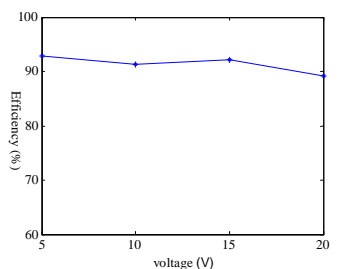

(c) Efficiency and voltage characteristics

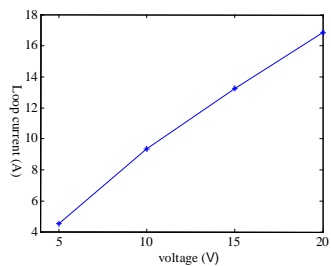

(d) Loop current and voltage characteristics

FIGURE IV. : RELATIONSHIP CHARACTERISTICS OF CLASS-E INVERTER 
As shown in fig. 4 (a), class E inverter circuit's advantages of efficiency and the efficiency would be affected by the frequency. But the actual effect had been maintained at more than $90 \%$. From the actual effect of the test, the efficiency was 1007 kHZ. From fig. 4 (b), the emission current resonance point and frequency most often had different advantages, needing to be compromised. From fig. 4 (c), With the increase of voltage of the launch, the overall efficiency had a downward trend. But it had little effect and the overall efficiency also remained at around 90\%. From fig. 4 (d), it could be seen that the transmitter loop current and voltage were into a stable linear relationship. So high-performance transmitter circuit could be got, whose output power was adjustable. It could be seen that the transmitter circuit performance is stable with a high frequency, high efficiency and high power output through the experimental data.

\section{WIRELESS TRANSMITTER POWER SUPPLy SySTEM PERFORMANCE TEST AND CONTRAST}

By optimization design, getting the high-performance transmitter coil in the self-induction of 60uh, the internal resistance of $1.1 \Omega$ when it was $1 \mathrm{MHZ}$. The detailed design parameters of class E inverter were shown in table 1. Fig. 5 (a) and fig. 5 (b) showed the class $E$ inverter and experimental platform, respectively.

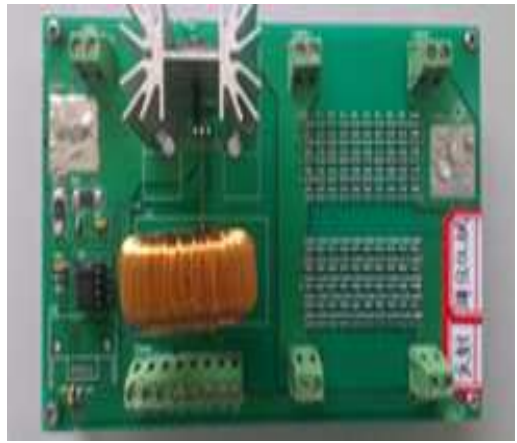

(a) Class E inverter board

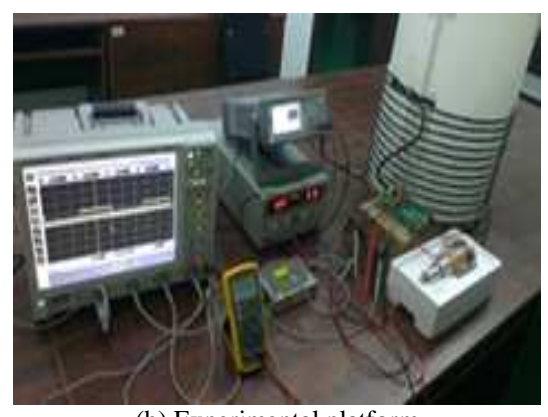

(b) Experimental platform

FIGURE V. EXPERIMENTAL PLATFORM AND CLASS-E INVERTER
TABLE I. TRANSMitTer PARAMETERS AND PERFORMANCE BASED ON CLASS-E INVERTER.

\begin{tabular}{|c|c|c|c|}
\hline \multicolumn{2}{|c|}{$\begin{array}{c}\text { The transmitter parameters and } \\
\text { electronic devices }\end{array}$} & \multicolumn{2}{|c|}{$\begin{array}{c}\text { The transmitter } \\
\text { performance }\end{array}$} \\
\hline $\begin{array}{l}\text { The power } \\
\text { supply } \\
\text { voltage }\end{array}$ & $\begin{array}{lr}\text { High power adjustable } \\
\text { switch } & \text { power } \\
\text { supply15V } & \end{array}$ & $\begin{array}{l}\text { Supply } \\
\text { current }\end{array}$ & $6.8 \mathrm{~A}$ \\
\hline Choke coil & $\begin{array}{l}3 \mathrm{mH} \text { (current coil with } \\
\text { magnetic core) }\end{array}$ & $\begin{array}{l}\text { Transmitter } \\
\text { current }\end{array}$ & $13.2 \mathrm{~A}$ \\
\hline Frequency & $1005 \mathrm{kHZ}$ & $\begin{array}{l}\text { Power } \\
\text { power }\end{array}$ & $102 \mathrm{~W}$ \\
\hline $\begin{array}{l}\text { Resonant } \\
\text { capacitor }\end{array}$ & $\begin{array}{l}0.424 \mathrm{nF} \text { High voltage } \\
\text { vacuum capacitor }\end{array}$ & $\begin{array}{l}\text { Transmit } \\
\text { power }\end{array}$ & $96 \mathrm{~W}$ \\
\hline $\begin{array}{l}\text { Parallel } \\
\text { capacitor }\end{array}$ & $\begin{array}{l}\text { 20nF High voltage } \\
\text { capacitors }\end{array}$ & $\begin{array}{l}\text { The } \\
\text { switching } \\
\text { voltage }\end{array}$ & $189 \mathrm{~V}$ \\
\hline MOS tube & $\begin{array}{l}\text { IXTQ96N20P High } \\
\text { frequency and high } \\
\text { power MOS tube }\end{array}$ & Efficiency & $95 \%$ \\
\hline Driver & $\begin{array}{l}\text { IXDD414 The driver } \\
\text { chip }\end{array}$ & & \\
\hline Heat sink & $\begin{array}{l}\text { L MOS suitable heat } \\
\text { sink }\end{array}$ & & \\
\hline $\begin{array}{c}\text { Transmitting } \\
\text { coil }\end{array}$ & $\begin{array}{l}1800 \text { shares of } 12 \\
\text { stranded coil turns, } \\
2.6 \mathrm{~cm} \text { of spacing, } \\
40 \mathrm{~cm} \text { of diameter, } \\
30 \mathrm{~cm} \text { in height }\end{array}$ & & \\
\hline
\end{tabular}

\section{A. Received Power and Position Stability Test}

To test the transmitter location stability and practical received power, wireless power supply system was overall implemented and tested. The receiving coil was 78 single strands of copper coils with coils magnetic core of nickel material. The self-induction of coil was $124 \mathrm{uH}$ and the coil resistance was $78 \Omega$. Doing the harmonic compensation of 1 MHZ for the coil and compensation capacitance was $0.219 \mathrm{nF}$.

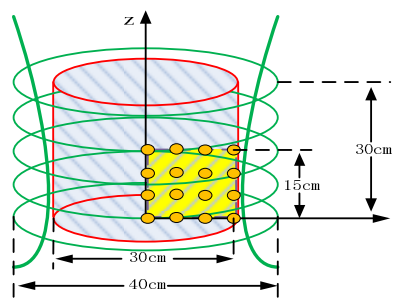

FIGURE VI. RECEIVING END OF THE TEST SITE

Transmitter power supply voltage was be taken as $5-15 \mathrm{v}$ to test respectively. The receiving end load respectively took $200 \Omega, 500 \Omega$ and $1000 \Omega$. And the measured values were $206 \Omega$, $499 \Omega, 1026 \Omega$. The blue shaded part could be contacted in actual work of the capsule robot in Fig.6. Because of symmetry of the coil, yellow points in the figure of uniform sampling were selected to test the received power.

From fig. 7 (a)-(c), in the case of a certain input voltage, the received power was basically stable. Power supply voltage was proportional to the received power. And power supply were respectively taken as $5 \mathrm{v}, 10 \mathrm{v}, 15 \mathrm{v}$ when the average received power were $285 \mathrm{~mW}, 1.09 \mathrm{~W}, 2.24 \mathrm{~W}$, respectively. As shown in fig. 7 (d), the location of stability under the condition of different load and different voltage changed when the power supply was different. But it was generally 
near an average and the optimal position of case stability could be as high as $87 \%$.

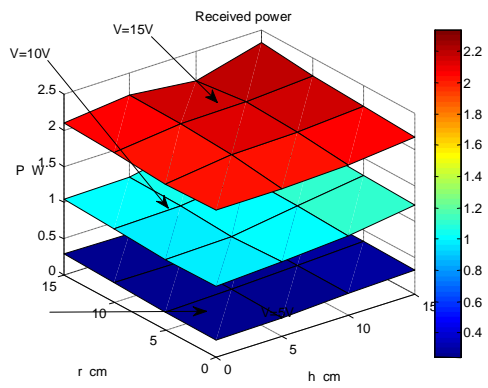

(a) The received power load of $206 \Omega$

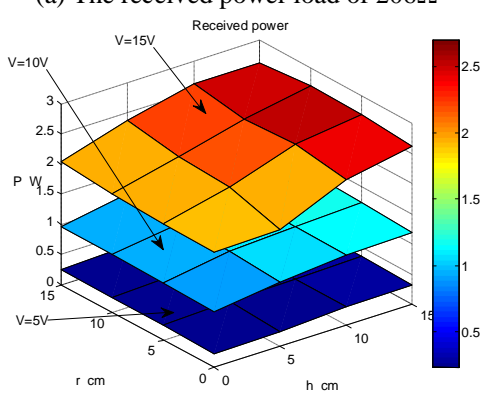

(b) The received powerof a of a load of $499 \Omega$

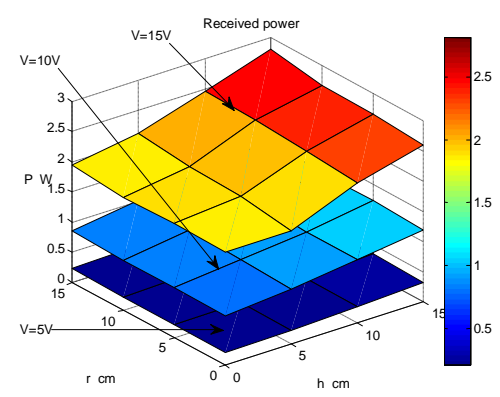

(c) The received power of a load of $1026 \Omega$

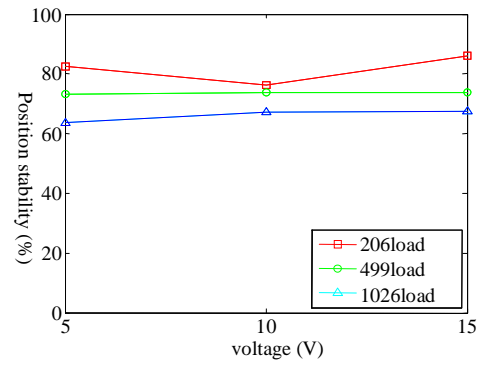

(d) The type and location of the load in case of different voltage stability FIGURE VII. TEST RESULTS OF THE R1ECEIVED POWER AND POSITIONAL STABILITY

\section{B. Performance Contrast}

By the optimization design and implementation, the specific data related to the topic was compared to the existing data. It could be seen from table 2, the contrast results of Shanghai Jiao Tong University, the work frequency, loop current, efficiency, receiving ascension. A comparison among the results of the university of leuven in Belgium, the corresponding performance optimization was improved. The comparison proved the superiority of the design.

TABLE II.

DATA COMPARISON.

\begin{tabular}{|c|l|l|l|}
\hline & $\begin{array}{c}\text { Optimization } \\
\text { design of the } \\
\text { transmitter }\end{array}$ & $\begin{array}{c}\text { Shanghai } \\
\text { Jiaotong } \\
\text { University Xin } \\
\text { Wenhui }\end{array}$ & $\begin{array}{c}\text { University of } \\
\text { Leuven in } \\
\text { Belgium }\end{array}$ \\
\hline Frequency & $1005 \mathrm{kHZ}$ & $400 \mathrm{kHZ}$ & $1050 \mathrm{kHZ}$ \\
\hline Power supply & $15 \mathrm{~V}$ & $12 \mathrm{~V}$ & $52.4 \mathrm{~V}$ \\
\hline $\begin{array}{c}\text { Transmitter } \\
\text { electric } \\
\text { current }\end{array}$ & $13.2 \mathrm{~A}$ & $3 \mathrm{~A}$ & $10 \mathrm{~A}$ \\
\hline $\begin{array}{c}\text { Transmitter } \\
\text { power }\end{array}$ & $96.6 \mathrm{~W}$ & $12.5 \mathrm{~W}$ & $35 \mathrm{~W}$ \\
\hline $\begin{array}{c}\text { Received } \\
\text { power }\end{array}$ & $2.24 \mathrm{~W}$ & $0.38 \mathrm{~W}$ & $0.213 \mathrm{~W}$ \\
\hline $\begin{array}{c}\text { Transmitter } \\
\text { efficiency }\end{array}$ & $94.7 \%$ & $80 \%$ & $88 \%$ \\
\hline $\begin{array}{c}\text { Position } \\
\text { stability }\end{array}$ & $87 \%$ & $81.3 \%$ & \\
\hline
\end{tabular}

To sum up, from the test results and analysis stated above, this design of the capsule robot system for wireless power transmitting terminal achieved the ideal effect. The transmission power, efficiency and frequency were high. The mean received power could be as high as $2.24 \mathrm{~W}$. Its position stability was up to $87 \%$ and the transmission power was adjustable and stable. In this article, the design of the transmitting terminal performance could meet the needs of most of the micro load network to drive the capsule robot to realize the technology of multi-function, high precision, low risk of nondestructive gastroscope inspection.

\section{REFERENCES}

[1] Abedi, A., Power-efficient-coded architecture for distributed wireless sensing. International Esports Tournament Wireless Sensor Systems, 1(3), pp. 129-136, 2011.

[2] Shan, J., Georgakopoulos, S.V., Optimum wireless power transmission through reinforced concrete structure. The 2011 IEEE International Conference on Radio Frequency Identification, pp. 50-56, 2011.

[3] Covic, G.A., Boys, J.T., Inductive power transfer. Proceedings of the IEEE, 101(6), pp. 1276-1289, 2013.

[4] Nagendra, G.R., Boys, J.T., Covic, G.A., Riar, B.S., Sondhi, A., Design of a double coupled IPT EV highway. The 39th Annual Conference of the IEEE Industrial Electronics Society, pp. 4606-4611, 2013

[5] Marques, H., Borges, B., Ramos, P., Martins, A., Contactless battery charger for composite humidity and temperature wireless sensors. International Conference on Computer as a Tool, pp. 1-4, 2011.

[6] Lee, H.G., Choi, M.K., Shin, B.S., Reducing redundancy in wireless capsule endoscopy videos. Computers in Biology and Medicine, 43(6), pp. 670-682, 2013.

[7] Imura, T., Study on maximum air-gap and efficiency of magnetic resonant coupling for wireless power transfer using equivalent circuit. Industrial Electronics, pp. 3664-3669, 2010.

[8] H.J. Liang, Design and Research of the capsule endoscope drive system. Guang Zhou: South China University of Technology, 2012.

[9] Gao Huang, Miniature robot system colonic disease clinics and Experimental Research. Shang Hai: Shanghai Jiaotong University, 2012. 
[10] Shen Hui, Circuit and its application based on vibration energy recovery piezoelectric materials. Nan Jing: Nanjing University of Aeronautics and Astronautics, 2010.

[11] Xinsong Li, Electromagnetic induction principle of underwater noncontact power transmission technology based on research. Hang Zhou: Zhejiang University, 2010.

[12] Fujimoto, J., Suzuki, A., Power monitoring using wireless sensor nodes as an effective contribution to power saving in convenience stores. The 2012 Electronics Goes Green, pp. 9-12, 2012.

[13] G. Wu, Optimal Design of high efficiency, high power density

magnetic components. Harbin: Harbin Institute of Technology, 2012. 